\title{
¿Cómo reportar casos clínicos?
}

\author{
How to report clinical cases?
}

$\mathrm{D}$ urante mucho tiempo no fue bien visto que las revistas publicaran reportes de casos clínicos, actualmente se les ha dado reconocimiento por sus beneficios potenciales, tales como promover una buena práctica, ser vehículos para entregar mensajes concisos en cuanto al manejo clínico de alguna patología, para la enseñanza, para emprender estudios de investigación y sobre todo para iniciarse en el arte de publicar. ${ }^{1}$

Los casos clínicos ayudan a ilustrar cómo se aplican las recomendaciones de guías de práctica clínica o revisiones sistemáticas.

De acuerdo con la Guía CARE un reporte de caso o caso es una narración que describe un problema médico que se presentó en un paciente o varios pacientes con fines científicos o de educación médica.

Los reportes de casos clínicos son comunes y representan un creciente número de artículos en las revistas médicas; sin embargo, no todos tienen la misma calidad. Al escribir sobre un caso clínico los autores deben apegarse a ciertos lineamientos. No es fácil para el editor o editores, lo mismo que para revisores, sugerir adecuaciones a los casos o rechazar una publicación de este tipo..$^{2,3}$

Para el reporte de caso clínico se adoptará una metodología con un orden lógico.

A continuación haremos algunas sugerencias para elaborar un reporte de caso clínico.

Se recomienda incluir cinco autores como máximo que hayan participado en la elaboración del artículo y no sólo en el manejo del paciente. Si alguien sólo participó en el diagnóstico, tratamiento, etc., se anotará su nombre en la lista de agradecimientos. ${ }^{2,3}$

Respecto de los créditos de los autores el Comité Internacional de Editores de Revistas Médicas señala que la contribución debe basarse en:

- El diseño, concepto, adquisición de los datos o análisis e interpretación de los mismos.

- El borrador del artículo o en la revisión del contenido.

- La aprobación de la versión final.

- El acuerdo de ser responsable de todos los aspectos del trabajo para asegurar que las interrogantes relacionadas con la exactitud o integridad de cualquier parte del trabajo se investiguen adecuadamente y se resuelvan.

Según la Guía CARE el título debe incluir el término "caso clínico" o "serie de casos" además de "síntomas", "diagnóstico", "intervención", "prueba", etcétera.

En cuanto a las palabras clave relacionadas con el caso, se sugiere de tres a cinco. 
El resumen debe contener una introducción que exponga por qué el caso es importante y en qué contribuye.

La presentación del caso describe los principales síntomas, hallazgos clínicos, el o los diagnósticos y procedimientos, los resultados y la conclusión, lo anterior no deberá exceder de 250 palabras.

En la introducción se destaca lo más relevante de la literatura médica respecto del caso clínico de forma resumida.

Si se tratara de un solo paciente, deberá especificarse información demográfica (género, edad, ocupación), síntomas principales, si es el caso historia familiar, estilo de vida, dietas, información genética, comorbilidades incluyendo procedimientos previos y sus resultados.

Tendrán que describirse los hallazgos relevantes de la exploración física.

Se sugiere elaborar una tabla o figura con una cronología de fechas y datos importantes del caso.

Deben mencionarse los apoyos para el diagnóstico (laboratorio y gabinete), si aplica el pronóstico.

Asimismo, qué tipo de intervención se utilizó (farmacológico, quirúrgico, preventivo) y si se prescribieron medicamentos, qué dosis, qué duración.

En resultados y seguimiento, reportar si surgieron eventos adversos.

En la parte de la discusión se detallan las fortalezas y debilidades en el manejo del caso y se establece una comparación con la literatura médica existente y el mensaje principal que captará el lector del caso o casos.

El paciente deberá compartir su experiencia o perspectiva en la medida de lo posible.

El o los pacientes debieron dar su consentimiento, éste se tendrá a la mano en caso de ser solicitado por el editor, lo mismo que la aprobación por el Comité de Ética en Investigación del lugar de trabajo.

El reporte de caso clínico debe incluir conclusiones, evitando dar recomendaciones o manejo médico, ya que se trata de un caso o serie de casos.

Las referencias se citan en formato Vancouver que actualmente se conocen como recomendaciones del Comité Internacional de Editores de Revistas Biomédicas.

Con respecto a la revista Cirujano General los reportes de caso que recibamos se someterán a revisión con los siguientes criterios: casos raros, de presentación no común, nuevos padecimientos, en los que se haya aprendido del error o errores y cuyo resultado no haya sido el esperado.

\section{REFERENCIAS}

1. Available in: https://hub.wiley.com/community/exchanges/discover/blog/2013/06/05/ how-to-write-a-clinical-case-report

2. Gagnier JJ, Riley D, Altman DG, Moher D, Sox H, Kienle G. The CARE guidelines: consensus-based clinical case reporting guideline development. Dtsch Arztebl Int. 2013; 110: 603-608.

3. López HD, Torres FA. Recomendaciones para redactar, diseñar y estructurar una publicación de caso clínico. Rev Esp Med Quir. 2014; 19: 229-235.

\section{Dra. Abilene C. Escamilla Ortiz}

